\title{
Cloud Base Height Estimation from ISCCP Cloud-Type Classification Applied to A-Train Data
}

\author{
Yao Liang, ${ }^{1}$ Xuejin Sun, ${ }^{1}$ Steven D. Miller, ${ }^{2}$ Haoran Li, \\ Yongbo Zhou, ${ }^{1}$ Riwei Zhang, ${ }^{3}$ and Shaohui Li ${ }^{1}$ \\ ${ }^{1}$ College of Meteorology and Oceanography, National University of Defense Technology, Nanjing 211101, China \\ ${ }^{2}$ Cooperative Institute for Research in the Atmosphere, Colorado State University, Fort Collins, CO, USA \\ ${ }^{3}$ State Key Laboratory of Aerospace Dynamics, Xian 710043, China \\ Correspondence should be addressed to Xuejin Sun; xjsun2000@sina.com
}

Received 16 May 2017; Accepted 10 August 2017; Published 14 September 2017

Academic Editor: Nir Y. Krakauer

Copyright (C) 2017 Yao Liang et al. This is an open access article distributed under the Creative Commons Attribution License, which permits unrestricted use, distribution, and reproduction in any medium, provided the original work is properly cited.

\begin{abstract}
Cloud base height $(\mathrm{CBH})$ is an important cloud macro parameter that plays a key role in global radiation balance and aviation flight. Building on a previous algorithm, CBH is estimated by combining measurements from CloudSat/CALIPSO and MODIS based on the International Satellite Cloud Climatology Project (ISCCP) cloud-type classification and a weighted distance algorithm. Additional constraints on cloud water path (CWP) and cloud top height (CTH) are introduced. The combined algorithm takes advantage of active and passive remote sensing to effectively estimate $\mathrm{CBH}$ in a wide-swath imagery where the cloud vertical structure details are known only along the curtain slice of the nonscanning active sensors. Comparisons between the estimated and observed CBHs show high correlation. The coefficient of association $\left(R^{2}\right)$ is 0.8602 with separation distance between donor and recipient points in the range of 0 to $100 \mathrm{~km}$ and falls off to 0.5856 when the separation distance increases to the range of 401 to $600 \mathrm{~km}$. Also, differences are mainly within $1 \mathrm{~km}$ when separation distance ranges from $0 \mathrm{~km}$ to $600 \mathrm{~km}$. The CBH estimation method was applied to the $3 \mathrm{D}$ cloud structure of Tropical Cyclone Bill, and the method is further assessed by comparing CTH estimated by the algorithm with the MODIS CTH product.
\end{abstract}

\section{Introduction}

Clouds influence Earth's energy balance by reflecting incoming short-wave solar radiation and absorbing outgoing longwave thermal radiation [1-3] and comprise the main source of uncertainty in climate models [4]. As an acknowledgement of their inherent importance to forecast models and operational meteorology in general, Understanding Clouds was adopted as the theme of World Meteorological Day 2017 [5]. In particular, the cloud vertical structure (CVS) impacts the atmospheric circulation through determining the vertical gradient of radiative budget and latent heating $[6,7]$ and also represents a key parameter to the aviation community $[8,9]$. Gaining better insight on CVS, including parameters such as the cloud top height $(\mathrm{CTH})$, cloud base height $(\mathrm{CBH})$, and the cloud layer thickness (CLT), under various environmental conditions is thus crucial to the research and operational communities alike. This paper focuses on satellite-based estimation of $\mathrm{CBH}$ of the topmost cloud layer, building upon a growing body of work that combines the strengths of passive and active sensors.

Many methods of retrieving $\mathrm{CBH}$ can be found in the literature. Surface-based sounding instruments such as ceilometers, millimeter-wavelength radar, radiosonde, and whole-sky infrared cloud-measuring systems provide good vertical resolution of $\mathrm{CBH}$ but for discrete location [10-15]. $\mathrm{CBH}$ information over the ocean from the surface-based observations is inherently sparse [16]. Satellite remote sensing is well established as a valuable platform for observing cloud structure globally. Efon et al. [17] analyzed CVS during active and break spells of the West African Summer Monsoon from CloudSat-CALIPSO measurements. Hutchison et al. $[18,19]$ present a satellite-based method for CBH retrieval for the uppermost cloud layer, and the algorithm has been 
applied to $\mathrm{CBH}$ products of the Visible Infrared Imager Radiometer Suite (VIIRS). Fitch et al. [20] and Seaman et al. [21] evaluated the $\mathrm{CBH}$ retrieval performance, finding that VIIRS CBH retrieval does not meet the performance specifications defined by the Joint Polar Satellite System (JPSS). To address the issue, Noh et al. [22] propose an alternative $\mathrm{CBH}$ estimation method via a semiempirical method that relates CLT to the Cloud Water Path (CWP), with relationship between the two conditioned on CTH. The method has been demonstrated to meet specifications and has been implemented provisionally as part of NOAA's enterprise operational cloud product system.

Satellite-based active remote sensing (e.g., radar and lidar) can acquire accurate CVS information, but currently available systems provide only nadir-viewing, nonscanning (and hence, nonvolumetric) cross-sections (or "curtain slices") through the atmosphere. While passive remote sensing (e.g., scanning imaging radiometers) provides cloud top information over a relatively large spatial swath, the nature of passive observations presents inherent challenges for retrieving CLT and deriving CBH [20-22]. The National Aeronautics and Space Administration (NASA) A-Train satellite constellation has Aqua/MODIS, CloudSat/CPR, and CALIPSO/ CALIOP remote sensing instruments, providing the convenience of observing $\mathrm{CBH}$ with a combination of active and passive sensors [23-25].

Forsythe et al. [15] estimate $\mathrm{CBH}$ for regional domains, combining with ground-based radar data and GOES satellite data. Their algorithm performs better when using cloud types as a constraint than when estimates are based simply on unconstrained interpolations. However, due to the limited coverage of ground-based radar systems, their technique is limited to low clouds, residing below about $3 \mathrm{~km}$ above the surface. Barker et al. [26] estimate CVS using a radiationsimilarity approach based on thermal infrared and visible channels to relate donor pixels (from the active sensor) to recipient pixels in the surrounding region. Sun et al. [25] proposed a spectral matching method based on the cloud top pressure constraint for further accurate estimation of $\mathrm{CBH}$. Miller et al. [27] propose a cloud-type-dependent decorrelation-length and distance-weighting method to reduce CVS estimation error due to dramatic changes in CVS based on regional clouds of a similar type having similar morphological properties. Here, CloudSat-defined cloud categories: cirrus, altostratus, stratus, stratocumulus, cumulus, nimbostratus, and deep convection. As demonstrated by [27], application of these relationships to observations which may not provide the same suite of cloud types requires remapping of cloud types, introducing a potentially large source of uncertainty.

With the objective of producing a wide range of $\mathrm{CBH}$ information, we examine the approach of Miller et al. [27] for $\mathrm{CBH}$ estimation using cloud-type classification of International Satellite Cloud Climatology Project (ISCCP). ISCCP was established in 1982 as the first project of the World Climate Research Program (WCRP) [28] and it is one of the most promising datasets in the global cloud climate research for parameter retrieval and climate analysis [29]. At present, the satellites used for generating ISCCP datasets include
NOAA-17/18, METOP-1, FY-2E, GOES-13/15, MTSAT-2, and METEOSAT-7/8/9. The algorithm is proposed as a complement to existing methods in the satellite-based remote sensing of $\mathrm{CBH}$. We assess the performance of this new $\mathrm{CBH}$ algorithm using A-Train data.

This paper is outlined as follows. Section 2 describes the data used here and ISCCP cloud-type definitions. Section 3 validates the feasibility of extending $\mathrm{CBH}$ based on ISCCP cloud type. Section 4 introduces the algorithm and the $\mathrm{CBH}$ estimation results are validated against CloudSat/CALIPSO in Section 5. Section 6 presents a 3D structure of a Tropical Cyclone and makes an assessment. Section 7 provides a conclusion and discussion.

\section{Data and Method}

2.1. CPR and CALIOP. The Cloud Profile Radar (CPR) is a $94 \mathrm{GHz}$ millimetric radar onboard CloudSat, its beam produces a profile footprint of about $1.7 \mathrm{~km}$ (along the track) $\times 1.4 \mathrm{~km}$ (across track), and profiles are reported every $1.1 \mathrm{~km}$ [30]. The CPR profiles have 125 vertical bins and each bin represents a distance of $240 \mathrm{~m}$ (oversampled from a $480 \mathrm{~m}$ range gate). The CPR can effectively penetrate optically thick clouds but tends to miss optically thin cloud whose reflectivity resides below the minimum sensitivity of about $-30 \mathrm{dBZ}$. The cloud-aerosol lidar with orthogonal polarization (CALIOP) instrument onboard CALIPSO holds the advantage over the CPR in observing optically thin cloud for its short wavelength but comes at the expense of resolving the vertical profiles of most meteorological cloud systems [31]. 2B-CLDCLASSLIDAR used in this paper is a combined CPR and CALIOP derived product that provides information on the number of cloud layers and $\mathrm{CTH}$ and $\mathrm{CBH}$ of each identified layer. Although CPR and CALIOP complement each other well, there are problems with CloudSat's ability to detect low clouds because of surface clutter [32]. To avoid surface contamination on cloud detection, following [33], only the information at heights $750 \mathrm{~m}$ above the terrain altitude is considered. In addition, observations are inaccurate for the case of heavy precipitation due to strong signal attenuation. At such, only the profiles which are flagged as nonprecipitation are used.

2.2. MODIS. The moderate-resolution imaging spectroradiometer (MODIS) sensors are carried onboard Terra and Aqua solar synchronous polar-orbiting satellites [34]. Aqua, CloudSat, and CALIPSO are members of the A-Train constellation, which fly in formation. The time interval between Aqua and CloudSat is only $1 \mathrm{~min}$, and the mean separation time between CloudSat and CALIPSO is $15 \mathrm{~s}$. The level 2 cloud production (MYD06, from Aqua) is used for combining observation. MYD06 provides cloud top pressure (CTP) and cloud optical thickness (COT) information with a horizontal resolution of $1 \mathrm{~km}$ for ISCCP cloud-type classification. In addition, the MODIS-retrieved CTP and cloud water path (CWP) are used simultaneously as a constraint for algorithm.

2.3. ISCCP Cloud-Type Definitions. ISCCP classifies clouds into nine categories based on CTP and COT. Low and middle cloud are recognized into liquid and ice phases; All high 


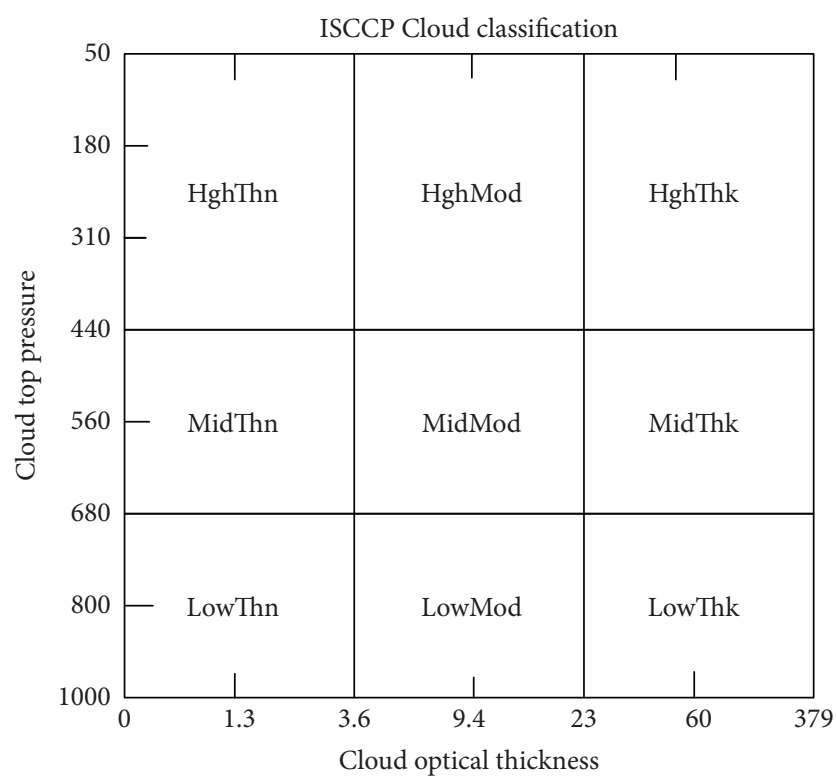

FIGURE 1: Cloud-type definitions used in this paper for daytime.

clouds are considered as being in the ice phase [35]. Since surface-defined cloud types (e.g., cirrus and stratus) do not correspond uniquely to defined cloud-type name of COTCTP space [36], following [37], we would rather name cloud types such as "HghThn" and "LowThk." Ranging vertically over low ( $1000 \leqslant \mathrm{CTP}<680 \mathrm{hPa}$, "Low"), middle ( $680 \leqslant \mathrm{CTP}$ $<440 \mathrm{hPa}$, "Mid"), and high ( $440 \leqslant \mathrm{CTP}<50 \mathrm{hPa}$, "Hgh") and optically over thin $(0<\mathrm{COT}<3.6$, "Thn"), moderate (3.6 $\leqslant$ COT < 23, "Mod"), and thick ( $23 \leqslant$ COT < 379, "Thk"), the ISCCP-like cloud-type definitions are used in this paper for daytime shown in Figure 1.

Following these ISCCP-based definitions, we use CTP and COT information from MYD06 to produce an ISCCPlike cloud-type classification for MODIS imagery. An example of MODIS cloud classification is shown in Figure 2. The overlaid black line indicates the location of the CloudSat ground track within the MODIS swath and hence the slice that provides relatively accurate cloud vertical profile information.

\section{Validation of the Feasibility of Extending CBH Based on ISCCP Cloud Type}

According to Miller et al. [27], regional clouds of a similar type may be expected to have similar morphological properties with the domain over which this assumption holds being a function of the cloud type. Therefore, they argue that it should be possible to extend the cloud base information observed by the active observations (considered as "donor" pixels) to the surrounding passive observations ("recipient" pixels) which share the same cloud type, and details are in next section. Doing so provides cloud base information with relatively large cloud coverage. The feasibility of applying this approach to ISCCP cloud types should be validated before the algorithm is established.

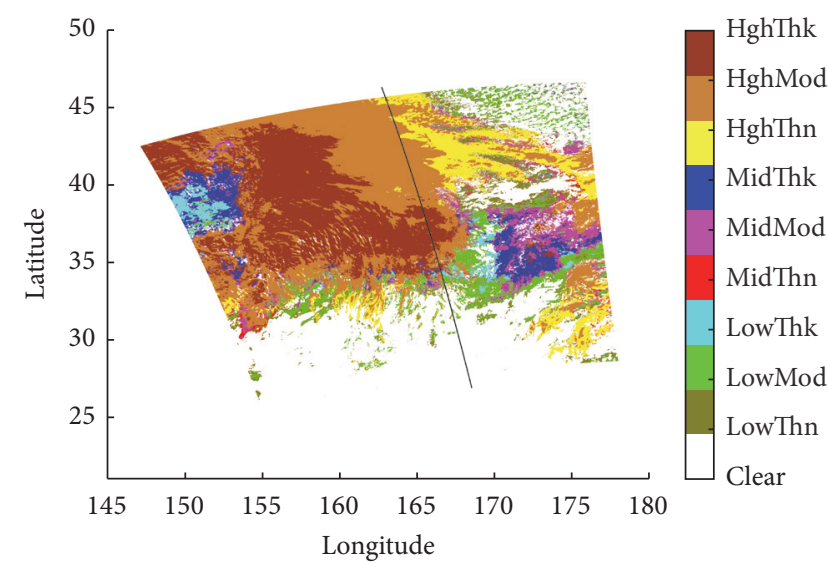

FIGURE 2: ISCCP cloud-type classification derived from MODIS data with CloudSat ground track overlaid for an example case collected at 02:15 UTC on 10 March 2010.

To evaluate whether $\mathrm{CBH}$ extending results based on ISCCP cloud-type-constrained outperforms simple nearestneighbor methods, experiments were carried out along the CloudSat/CALIPSO cross-section. We chose MODIS and CloudSat/CALIPSO matching data from March and June 2010 for experiments. To avoid uncertainty caused by variation of the underlying surface, only data over the Pacific Ocean were used in the experiments. Based on these matchups, the following comparison schemes were designed:

(1) Match CloudSat/CALIPSO and MODIS datasets in space and time. Because of different horizontal resolution, Wang et al. [37] find that over 75\% of the CloudSat/CALIPSO and MODIS collocated pixels/footprints are separated within $0.5 \mathrm{~km}$ distance and over $93 \%$ are within $0.6 \mathrm{~km}$. In order to carry out the most accurate comparison with the smallest spatial and temporal sampling biases, collocated pixels/footprints that are separated within $0.5 \mathrm{~km}$ distance are chosen.

(2) Classify the collocated pixels based on CTP and COT provided from MYD06, according to ISCCP cloudtype definitions in Figure 1.

(3) Consider only data identified as single-layer cloud profile by MODIS and CBH of the collocated CloudSat/CALIPSO data. If one footprint is identified as a multilayer cloud by CloudSat/CALIPSO, the CBH of the uppermost layer is recorded as the validation value. Wang et al. [37] find that only $60 \%$ of the singlelayer clouds identified by MODIS are consistent with CloudSat/CALIPSO. MODIS has difficulties observing the properties of the underlying cloud in some cases of the existence of multilayer clouds. CloudSat/CALIPSO are active remote sensing satellites with vertical profiling. Therefore, it is considered that $\mathrm{CBH}$ of the uppermost layer from CloudSat/CALIPSO is to be recorded.

(4) Select one pixel/footprint (denoted as REFER) from datasets derived from step (3), and then, respectively, 
away from REFER $10 \mathrm{~km}, 50 \mathrm{~km}, 100 \mathrm{~km}$, and $200 \mathrm{~km}$ along the same track find two pixels/footprints: (a) closest to REFER with same cloud type (denoted as TYPE); (b) closest to REFER no matter with any cloud type (denoted as DIST). Output the $\mathrm{CBH}$ of the REFER point as the referenced $\mathrm{CBH}$, and the $\mathrm{CBH}$ of TYPE and DIST are as the estimated values of the REFER point, respectively. Here, CBHs are all from collocated CloudSat/CALIPSO measured results. Repeat this process to get enough samples. If there was no condition to meet the DIST or TYPE, then no estimate was made at the REFER location.

(5) To evaluate the performance of the datasets (REFER, DIST, and TYPE) found in step (4), root mean square error (RMSE) statistics were used follows:

$$
\mathrm{RMSE}=\sqrt{\frac{\sum_{i=1}^{n}\left(H_{i}^{\prime}-H_{i}\right)^{2}}{n}},
$$

where $H_{i}^{\prime}$ and $H_{i}$ denote estimated and referenced $\mathrm{CBH}$, respectively.

Following these steps, we can compare the performance of cloud-type-constrained and simple nearest-neighbor methods for estimating $\mathrm{CBH}$. These $\mathrm{CBH}$ comparisons are presented as scatterplots of REFER versus DIST and REFER versus TYPE. We subdivided these results by screening distance between REFER and DIST/TYPE.

Figure 3 shows scatterplots of REFER CBH observations versus DIST (a) and TYPE (b), using the matching data restricted from the above steps. Figure 3(a) shows the DIST plots and Figure 3(b) contains the TYPE results. 1, 2, 3, and 4 denote the screening distance of $10 \mathrm{~km}, 50 \mathrm{~km}, 100 \mathrm{~km}$, and $200 \mathrm{~km}$, respectively. In each plot, the 1:1 line and RMSE are given.

The value of RMSE represents the goodness of fit; the smaller the value, the better the fit. The results indicate that the TYPE method is superior to DIST, with RMSE value being relatively smaller at various donor point distances, especially when the distance exceeds $50 \mathrm{~km}$. As expected from [27], RMSE increases with distance, so weighted distance is used for the algorithm in next section.

\section{4. "Constrained Maximum Donors" Algorithm for CBH Estimation}

4.1. Algorithm Description. From Section 3 and [27], we know that the performance of $\mathrm{CBH}$ estimation is related to cloud type and separation distance from reference points. At different distances, the standard deviation of the various types of $\mathrm{CBH}$ has different behaviors of variation. Following the example of [27], Figure 4 presents the dependence of mean standard deviation of the various ISCCP types of $\mathrm{CBH}$ on range from the point of observation, which was obtained by making statistics of A-Train matching data from the first day of every month in 2010.

In this section, a CBH estimation method based on cloud type and weighted distance constraints is described. Miller et al. [27] introduce a "Maximum Donors" approach for this weighting. The main idea of "Maximum Donors" is to select all of the points (donors) along the CloudSat track that share the same cloud type with that of the recipient point, starting from the minimum exclusion distance out to a maximum allowed distance and combine the CBHs from these donors using distance-dependent weightings (shown in Figure 5). The current algorithm is an extension of Maximum Donors that includes an additional CTP and CWP simultaneous constraint, namely, Constrained Maximum Donors. Sun et al. [25] suggest that cloud parameters retrievable by passive radiometers may help express cloud geometric information and develop a spectral matching method based on CTP constraint for estimating CBH. Similarly, Li and Sun [24] select the most appropriate donor to a recipient for estimating $\mathrm{CBH}$ based on CWP and CTP. We follow these approaches in assuming that clouds of the same type might be expected to share similar CWP and CTP. The assumption is tied closely to the cloud type and we use CTP and CWP as controlling factors may offer further improvement to estimation of $\mathrm{CBH}$ in some cases.

Following [27], a distance-weighting function is applied, based on the standard deviations computed for a given cloud type:

$$
W(d)=\frac{1}{\sigma^{2}(d)},
$$

where $d$ is the geometric distance in kilometers from donor to the recipient location and $\sigma(d)$ is the standard deviation of $\mathrm{CBH}$ on estimating distance from curve fits (shown in Figure 4).

Figure 5 shows a schematic of how the donor points are weighted in forming the final estimate. Again following [27], the estimated $\mathrm{CBH}$ at the recipient point is formed by

$$
H=\frac{\sum_{i=1}^{N} H(i) W\left(d_{i}\right)}{\sum_{i=1}^{N} W\left(d_{i}\right)},
$$

where $N$ represents the number of donor points and $H(i)$ is the measured $\mathrm{CBH}$ at donor point $i$. The variable $d_{i}$ denotes the geometric distance between donor point $i$ and the recipient point. $W\left(d_{i}\right)$ represents the weight of donor point $i$, per (2).

Our similarity constraint is introduced as follows:

$$
\left|\frac{\widehat{C}(\text { donor })-\widehat{C}(\text { recipient })}{\widehat{C}(\text { recipient })}\right| \leq \alpha,
$$

where $\widehat{C}$ (donor) and $\widehat{C}$ (recipient) are MODIS-retrieved cloud characteristics (e.g., CWP and CTP) of recipient and donor, respectively, and $\alpha$ is a constraint factor for allowing the maximum cloud characteristic differences between donor and recipient points. Sun et al. [25] consider the performance of $\mathrm{CBH}$ estimation for different values for $\alpha$, finding that $\alpha=$ 0.3 provides the most suitable value for his algorithm. The choices of $\alpha$ for Constrained Maximum Donors method will be discussed later. 


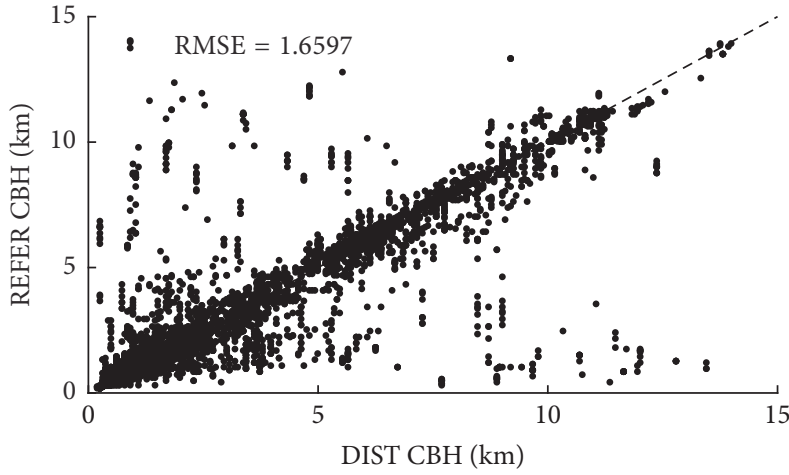

(a1)

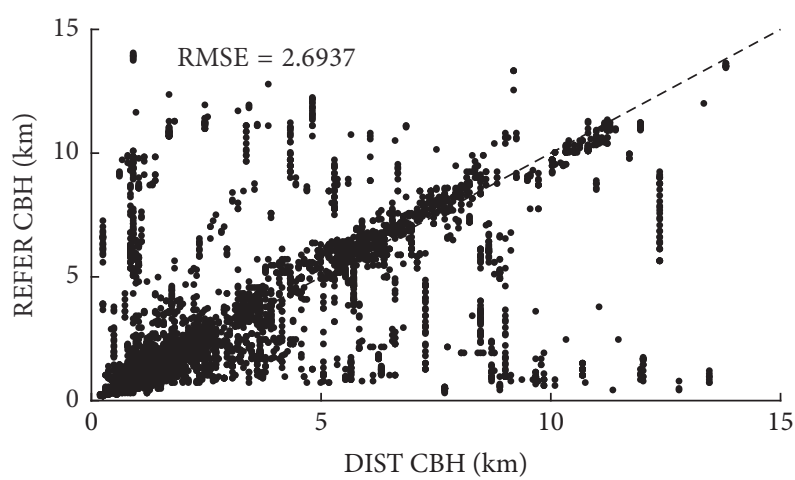

(a2)

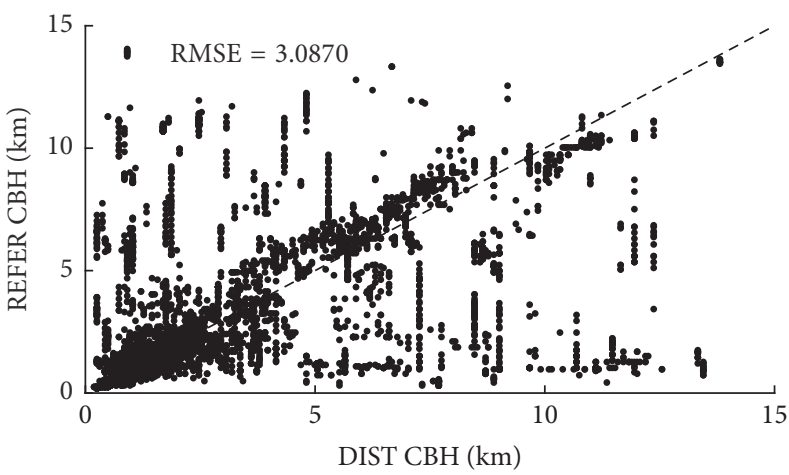

(a3)

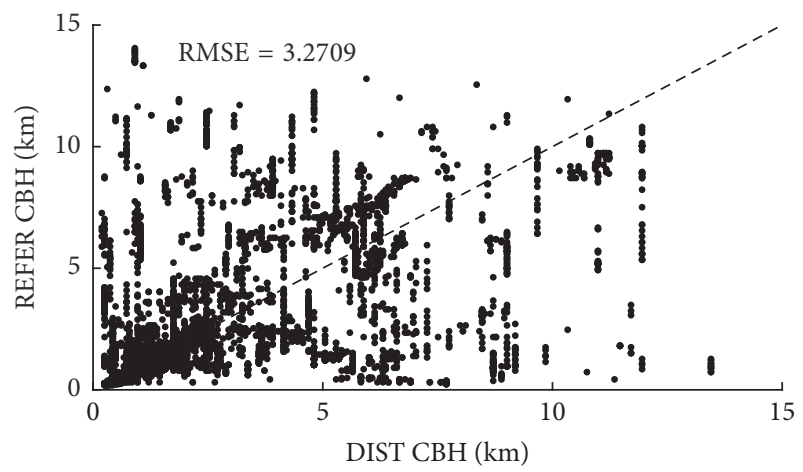

(a4)

(a)

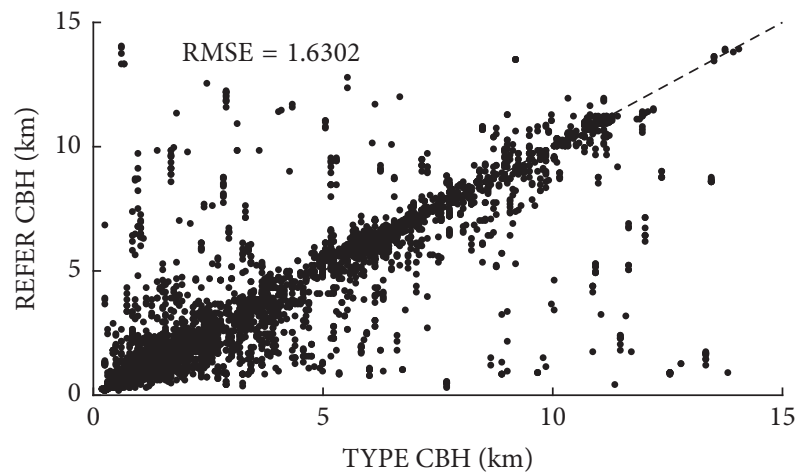

(b1)

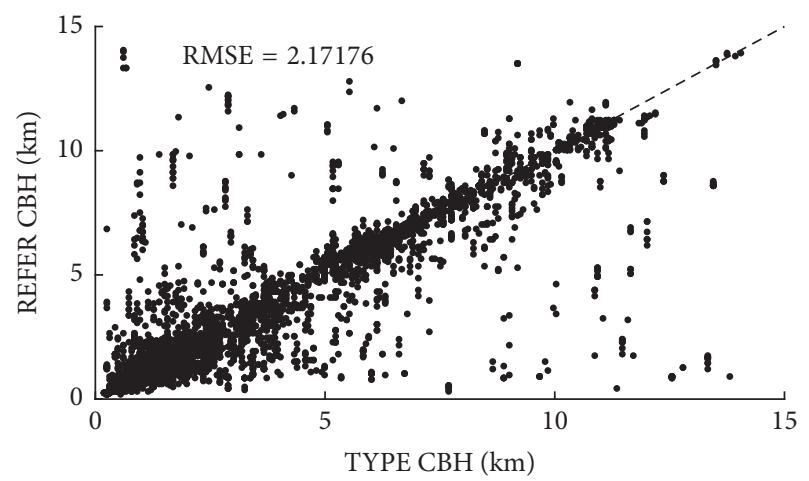

(b2)

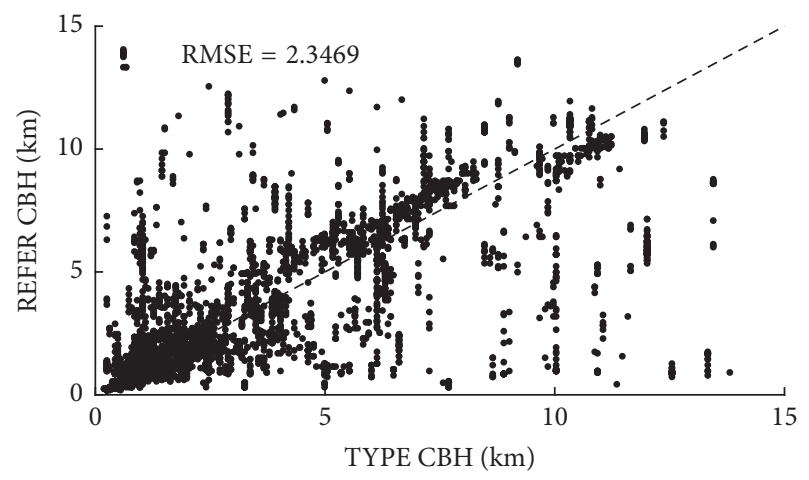

(b3)

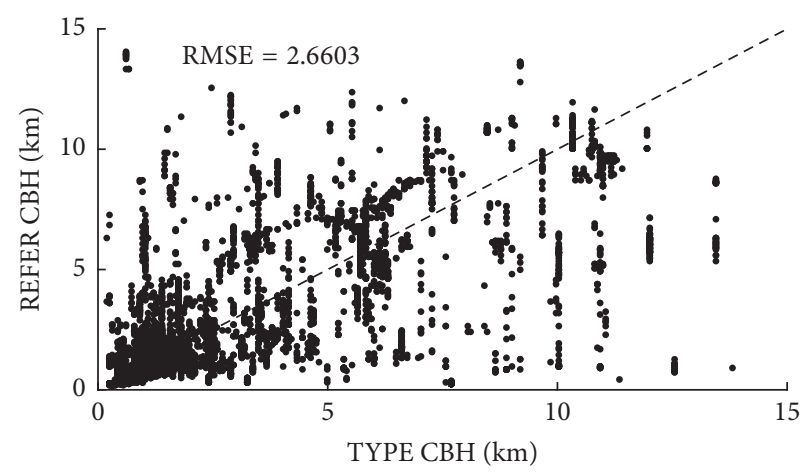

(b4)

(b)

FIgURE 3: Comparison CBH estimation of DIST (a) and TYPE (b). 1, 2, 3, and 4 denote donor point distances of $10 \mathrm{~km}, 50 \mathrm{~km}, 100 \mathrm{~km}$, and $200 \mathrm{~km}$, respectively. 


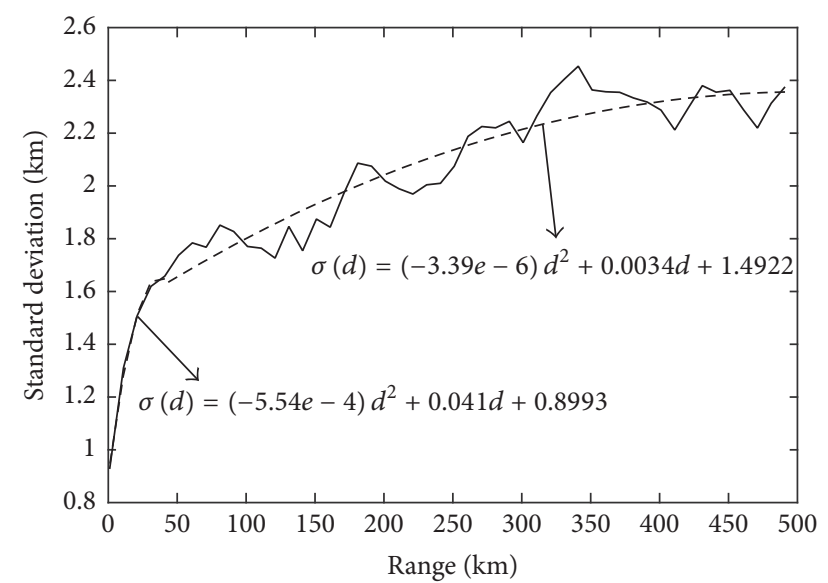

FIGURE 4: Dependence of mean standard deviation of $\mathrm{CBH}$ on range from the point of observation. The dashed fitted curve is a piecewise continuous function.

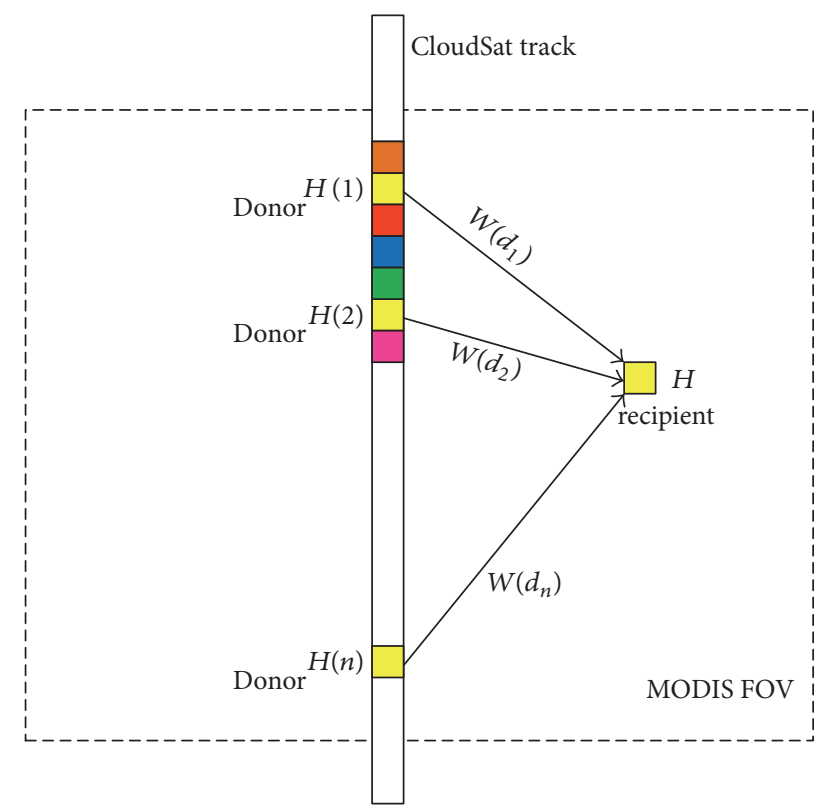

Figure 5: Conceptual rendering of CloudSat/CALIPSO ground tracks nested within the MODIS swath. Arrows map CBH typeconstrained donor points (colors denote different cloud types) along the active sensor track to the MODIS recipient point.

4.2. Discussion about the Constraint. In order to evaluate the performance of (4) for $\mathrm{CBH}$ estimation and determine the most suitable $\alpha$ for different constraints, experiments were carried out along the CloudSat/CALIPSO cross-section. Data from the second day of every month in 2010 were used in these experiments. Basically, an attempt was made to reconstruct $\mathrm{CBH}$ along the CloudSat/CALIPSO track by excluding the search for potential donors from a dataexclusion window in close proximity to the recipient. As such, the exclusion distance is equivalent to the smallest geometric distance between a recipient and the cross-sectional track. If fewer than three donor points were available within a given range, then no estimate was made for the recipient point. Root mean square error (RMSE) (shown in (1)) and mean deviation (MD) are used to evaluate performance of the different constraints. MD is defined as

$$
\mathrm{MD}=\frac{1}{n} \sum_{i=1}^{n}\left|H_{i}^{\prime}-H_{i}\right|
$$

where $H_{i}^{\prime}$ and $H_{i}$ denote estimated and observed $\mathrm{CBH}$, respectively. Effects of the constraints on estimating $\mathrm{CBH}$ were evaluated by

$$
\begin{aligned}
\eta_{\mathrm{MD}}(c) & =\frac{\mathrm{MD}_{0}-\mathrm{MD}_{c}}{\mathrm{MD}_{0}} \times 100 \%, \\
\eta_{\mathrm{RMSE}}(c) & =\frac{\mathrm{RMSE}_{0}-\mathrm{RMSE}_{c}}{\mathrm{RMSE}_{0}} \times 100 \%,
\end{aligned}
$$

where $\mathrm{RMSE}_{0}$ and $\mathrm{RMSE}_{c}$ denote RMSE of estimated CBH without constraint and with constraint, respectively; $\mathrm{MD}_{0}$ and $\mathrm{MD}_{c}$ denote $\mathrm{MD}$ of estimated $\mathrm{CBH}$ without constraint and with constraint, respectively. Meanwhile, the rate of Reduced Estimable Recipients (RER) is used and defined as

$$
\eta_{\mathrm{RER}}(c)=\frac{n\left(\text { recipient }_{0}\right)-n\left(\text { recipient }_{c}\right)}{n\left(\text { recipient }_{0}\right)} \times 100 \%,
$$

where $n\left(\right.$ recipient $\left._{0}\right)$ and $n$ (recipient $\left._{c}\right)$ denote the number of samples of effect estimable recipients without constraint and with constraint, respectively.

Figure 6 shows variations of $\eta_{\mathrm{MD}}, \eta_{\mathrm{RMSE}}$, and $\eta_{\mathrm{RER}}$, respectively, for CTP and CWP constraints as a function of exclusion distances $(50,100,200$, and $400 \mathrm{~km})$ when $\alpha=0.3$. These figures show that two constraints almost always have a positive effect on $\mathrm{CBH}$ estimation. In general, improvements for $\mathrm{CBH}$ estimation with a CWP constraint are more significant than with a CTP constraint, and the decrease of estimable recipients is larger for CWP constraint. Although the CTP constraint does not perform as well as the CWP constraint, it has an obvious improvement over no constraint at all. Hence, both CTP and CWP were utilized here as constraints.

In order to select the suitable $\alpha$ for constraints, the performance of estimating $\mathrm{CBH}$ with CTP constraint for different values of $\alpha$ was analyzed, shown in Figure 7. As the exclusion distances increase, $\eta_{\text {RER }}$ gradually increases. As expected, a stricter constraint results in fewer available recipients. Performances for $\alpha=0.1$ exhibit the largest $\eta_{\mathrm{MD}}$ and $\eta_{\mathrm{RMSE}}$, that is, best estimates (6), in estimating CBH when exclusion distances exceed $100 \mathrm{~km}$. However, when distances are $50 \mathrm{~km}$, it has the worst performance and imparts a negative effect on results. A stricter constraint results in better estimates, but too strict a constraint worsens estimation of $\mathrm{CBH}$ in some cases [25]. The aim of this research is to achieve $\mathrm{CBH}$ estimation with large coverage. As such, the principle objective of constraint is to get a larger $\eta_{\mathrm{MD}}$ and $\eta_{\mathrm{RMSE}}$ with relatively small $\eta_{\mathrm{RER}}$. Here, when $\alpha=0.2$, the CTP constraint always has a positive effect on $\mathrm{CBH}$ estimation and $\eta_{\mathrm{MD}}$ and $\eta_{\text {RMSE }}$ are larger, comparing with $\alpha=0.3, \alpha=0.4$, and $\alpha$ $=0.5$. Meanwhile, its associated $\eta_{\text {RER }}$ does not exceed $15 \%$. Therefore, $\alpha=0.2$ was selected for the CTP constraint. 

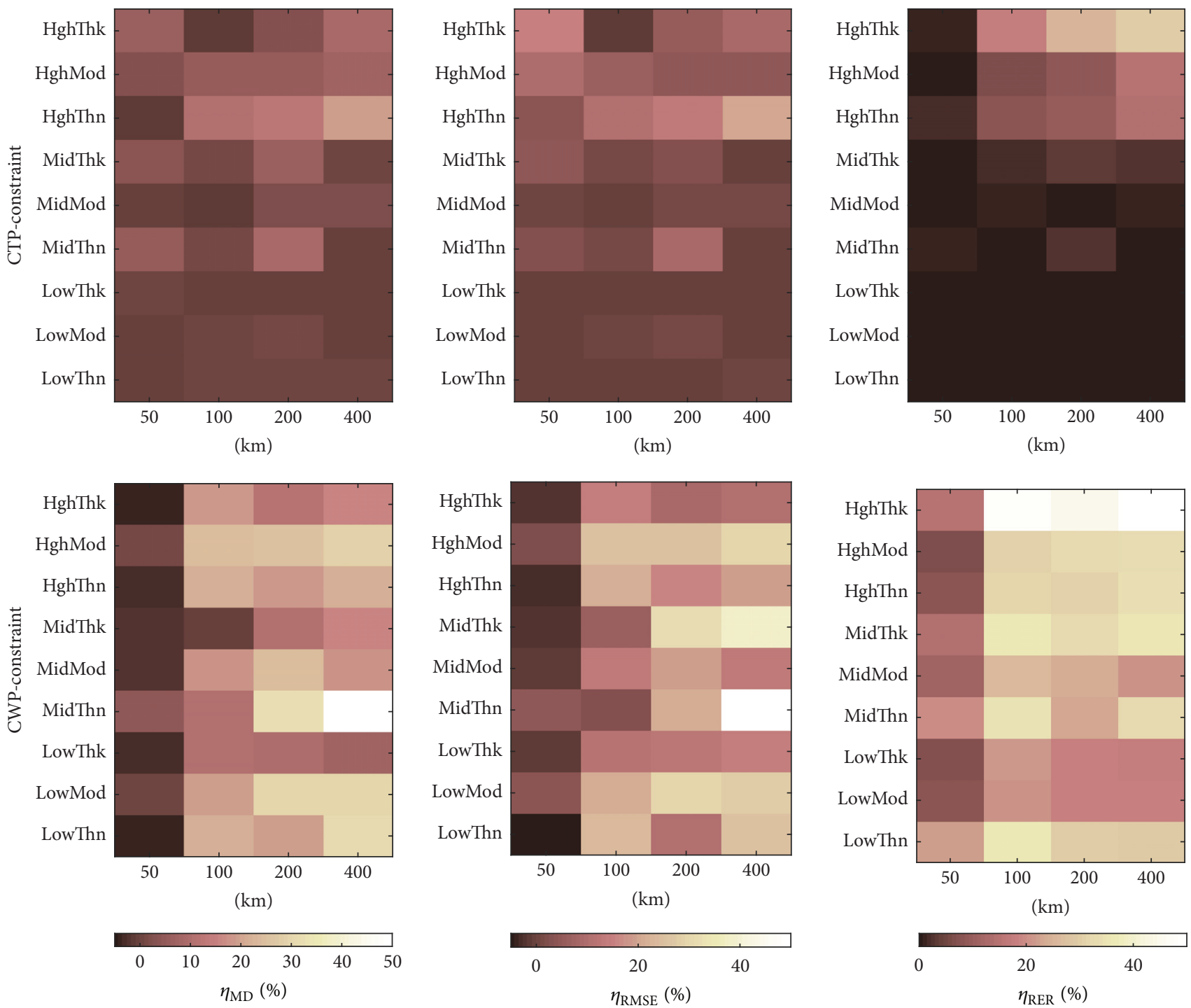

FIGURE 6: Statistical performances of CTP and CWP constraints for CBH estimation as functions of exclusion distances (50, 100, 200, and $400 \mathrm{~km}$ ) when $\alpha=0.3$. The three columns show (left to right) $\eta_{\mathrm{MD}}(\%), \eta_{\mathrm{RMSE}}(\%)$, and $\eta_{\mathrm{RER}}(\%)$, respectively. Within each panel, the nine ISCCP cloud types are labeled.

Similar to Figure 7, the performance of estimating $\mathrm{CBH}$ with CWP constraint for different values of $\alpha$ is shown in Figure 8. Performances for $\alpha=0.1$ and $\alpha=0.2$ have larger $\eta_{\mathrm{MD}}$ and $\eta_{\mathrm{RMSE}}$ in estimating $\mathrm{CBH}$ when exclusion distances exceed $100 \mathrm{~km}$ but have a worse performance and negative effect when distances are $50 \mathrm{~km}$. When $\alpha=0.3, \eta_{\mathrm{MD}}$ and $\eta_{\mathrm{RMSE}}$ of the CWP constraint are positive at all distances and have a relatively high value. The corresponding $\eta_{\mathrm{RER}}$ does not exceed $35 \%$. Therefore, $\alpha=0.3$ was selected for the CWP constraint.

\section{CBH Validation against CloudSat/CALIPSO}

In order to quantify the algorithm's performance, 60 sets of CloudSat/CALIPSO and MODIS matching data from January to December in 2010 were selected. The $\mathrm{CBH}$ value of 2B-CLDCLASS-LIDAR was considered as true. We then proceed to search for donor points along the CloudSat track in the ranges of $0 \sim 100 \mathrm{~km}, 101 \sim 200 \mathrm{~km}, 201 \sim 400 \mathrm{~km}$, and $401 \sim 600 \mathrm{~km}$, respectively, using the algorithm described in Section 4.1 to estimate CBH. Similar to Section 4.2, if fewer than three donor points were available within a given range, then no estimate was made for the recipient point.

Scatterplots of the estimated and observed CBHs following this procedure are shown in Figure 9. It can be seen that the scattered values of the estimated and observed CBHs are concentrated in the vicinity of the 1:1 line denoting good agreement. As the donor point distances increase, the scatter points are gradually broadened, but even so most points accumulate around the $1: 1$ line. The coefficient of association $\left(R^{2}\right)$ is 0.8602 with separation distance between donor and recipient points in the range of 0 to $100 \mathrm{~km}$ and falls off to 

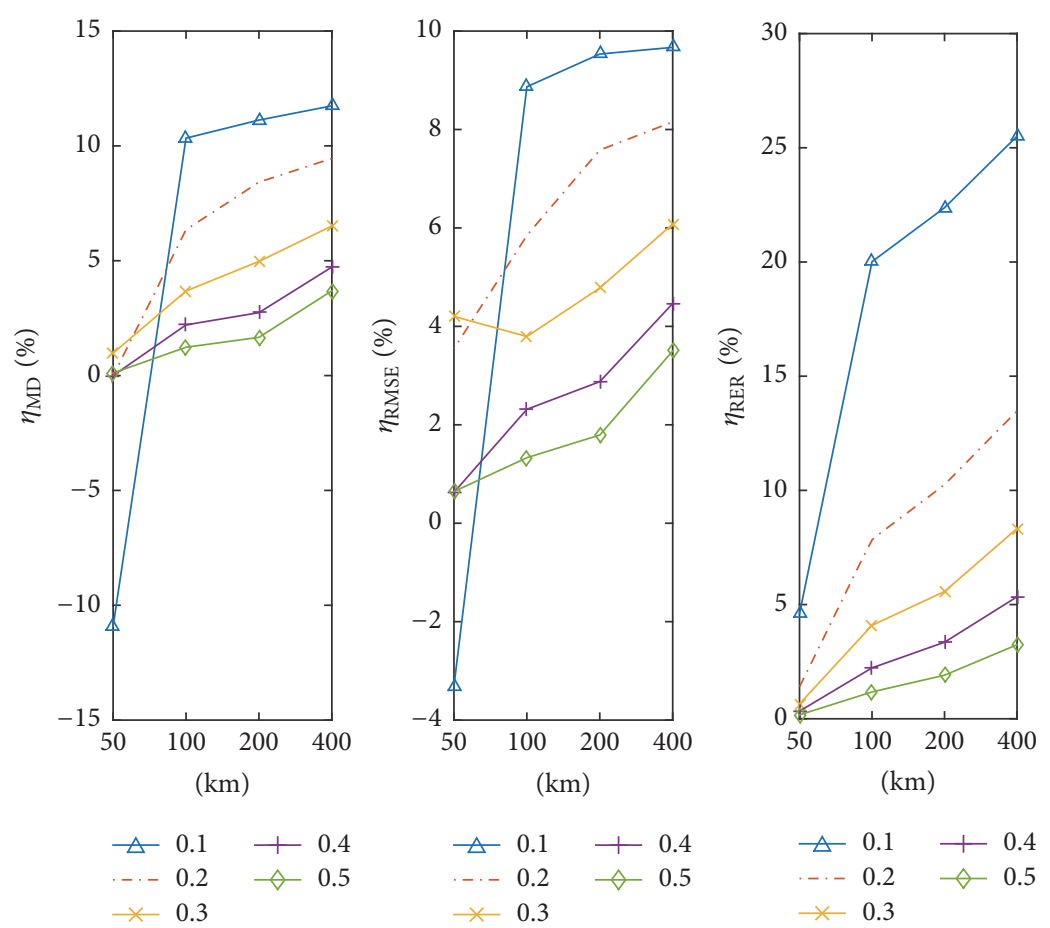

Figure 7: Variations of $\eta_{\text {MD }}(\%), \eta_{\text {RMSE }}(\%)$, and $\eta_{\text {RER }}(\%)$ as functions of exclusion distances $(50,100,200$, and $400 \mathrm{~km})$ for different values of $\alpha$ when CTP constraint.

0.5856 when the separation distance increases to the range of 401 to $600 \mathrm{~km}$. Also, the bias of estimation is generally within $\pm 0.1 \mathrm{~km}$ when separation distance is in the range of 0 to $600 \mathrm{~km}$.

For this same analysis, the probability density of differences between the estimated and observed $\mathrm{CBH}$ s was also calculated as a function of the different ranges. These distributions are shown in Figure 10. It can be seen that the absolute error is mainly within $1 \mathrm{~km}$, and the probability density function is approximately a normal distribution. The frequency of absolute error within $1 \mathrm{~km}$ is more than 0.9 in the range of 0 to $100 \mathrm{~km}$ and falls off to 0.5 when the separation distance increases to the range of 401 to $600 \mathrm{~km}$.

\section{Case Study}

6.1. 3D View of Tropical Cyclone Bill. As a final evaluation, we reconstruct the 3D cloud structure of a Tropical Cyclone, similar to Miller et al. [27] reconstruction of Super Typhoon Choi-Wan. For this case, Tropical Cyclone (TC) Bill in the North Atlantic, observed by A-Train at 23:11 UTC on August 19, 2009, was chosen. Figure 11 shows the ISCCP cloud-type classification of TC Bill, which is obtained by using MODIS CTP and COT. It can be seen that the cloud tops associated with TC Bill are characterized mainly by HghThn, HghMod, and HghThk types. Figure 12 shows the MODIS COT grayscale image of TC Bill. (a) is CloudSat ground track. (b) (e) are selected scans away from the CloudSat track by $100 \mathrm{~km}$, $200 \mathrm{~km}, 300 \mathrm{~km}$, and $400 \mathrm{~km}$, respectively.

Figure 13 illustrates the cloud typing and measured CloudSat/CALIPSO cloud profile along the track, along with four predictions of cloud geometric boundaries for the uppermost layer for the uppermost layer for arbitrary crosssections through TC Bill. Here, MODIS-derived CTH constrains cloud top, and the $\mathrm{CBH}$ is derived by the algorithm. Every profile is colored according to the ISCCP cloud type identified at cloud top. The horizontal scale of the entire cyclone is on the order of thousands of kilometers, while the vertical scale is on the order of 10 kilometers (characteristic depth of the troposphere).

6.2. Comparison with MODIS CTH Products. Because there is no reliable way to observe the full $3 \mathrm{D}$ cloud structure of a tropical storm, the estimates shown in Figure 13 cannot be validated directly. However, the reconstructed 3D cloud structure of TC Bill can be compared directly against the MODIS CTH product. CTH is an important cloud macrophysical parameter available from MODIS [38]. Here, we assess the performance of the algorithm by comparing CTH retrieved by the Constrained Maximum Donors estimate (applied to CTH instead of $\mathrm{CBH}$ ) with MODIS CTH product. Differences between the CTH retrievals of MODIS and CloudSat/CALIPSO are shown in Figure 14.

Figure 14 shows that MODIS and CloudSat/CALIPSO are generally consistent with one another with some isolated outlier regions $\left(11^{\circ} \mathrm{N} \sim 12^{\circ} \mathrm{N}, 14^{\circ} \mathrm{N} \sim 17^{\circ} \mathrm{N}, 18^{\circ} \mathrm{N} \sim 20^{\circ} \mathrm{N}\right.$, and $22^{\circ} \mathrm{N} \sim$ $\left.25^{\circ} \mathrm{N}\right)$. The comparison further reaffirms the findings of previous studies [39-41] that there exist biases between the active and passive CTH retrievals. Namely, active sensor CTH values tend to be higher than those of passive retrievals. This is because passive sensors detect an effective CTH that corresponds to an integrated optical depth of about unity 

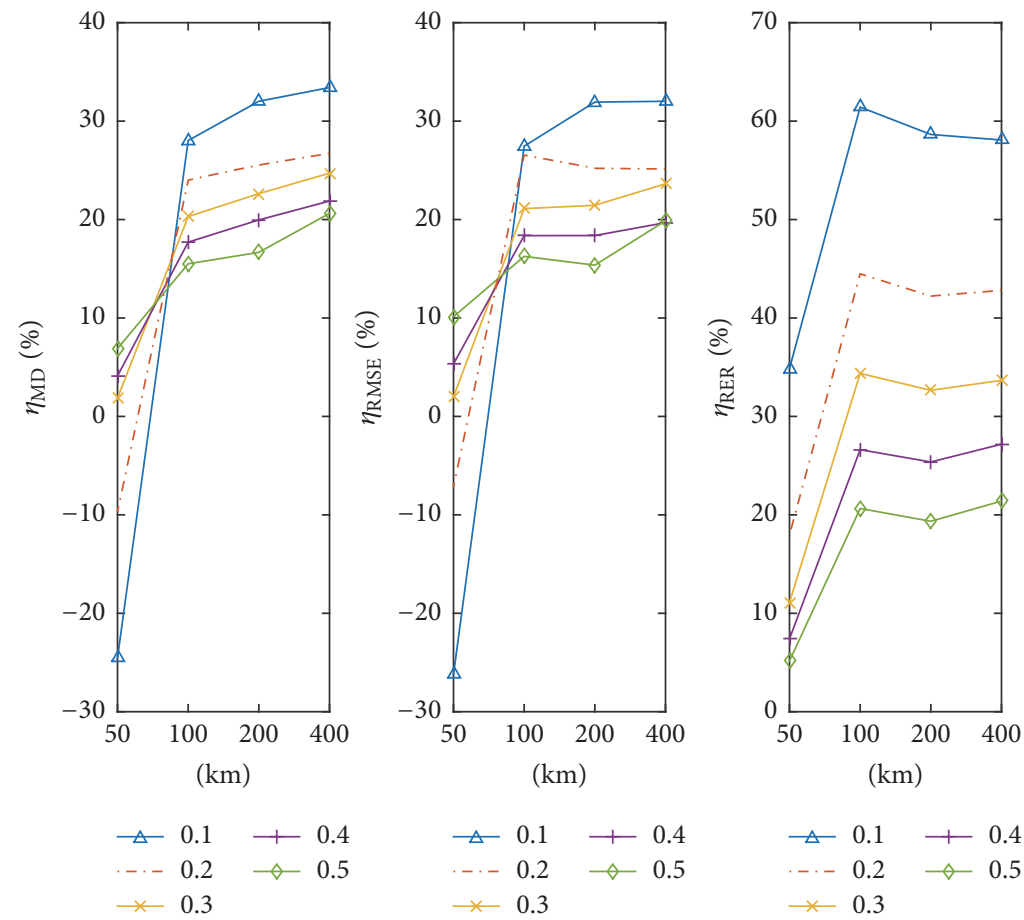

FIgURE 8: The same as Figure 7, but for CWP constraint.

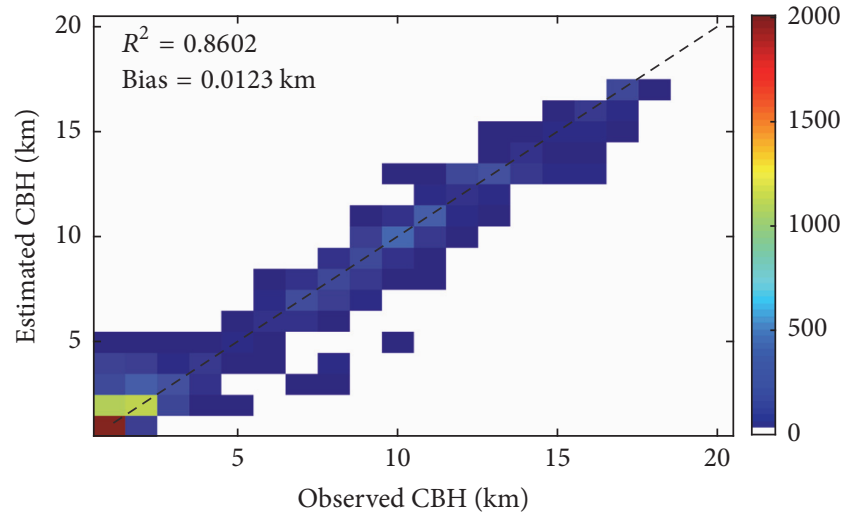

(a)

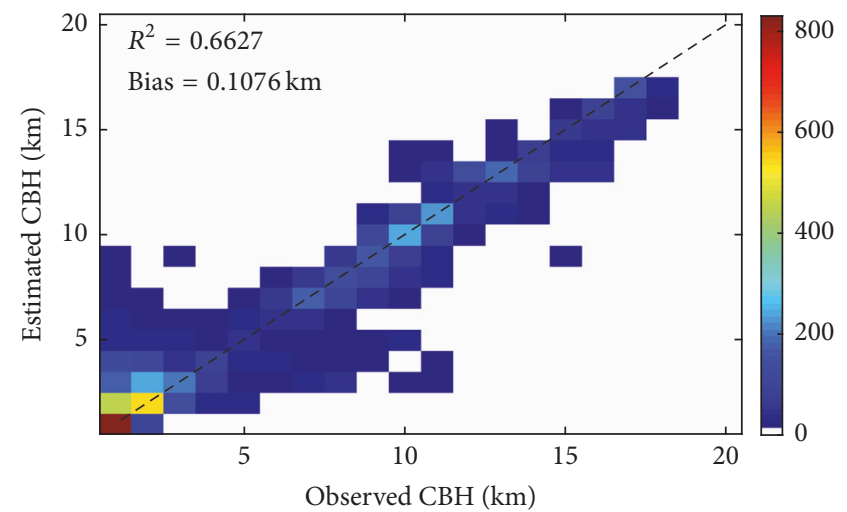

(c)

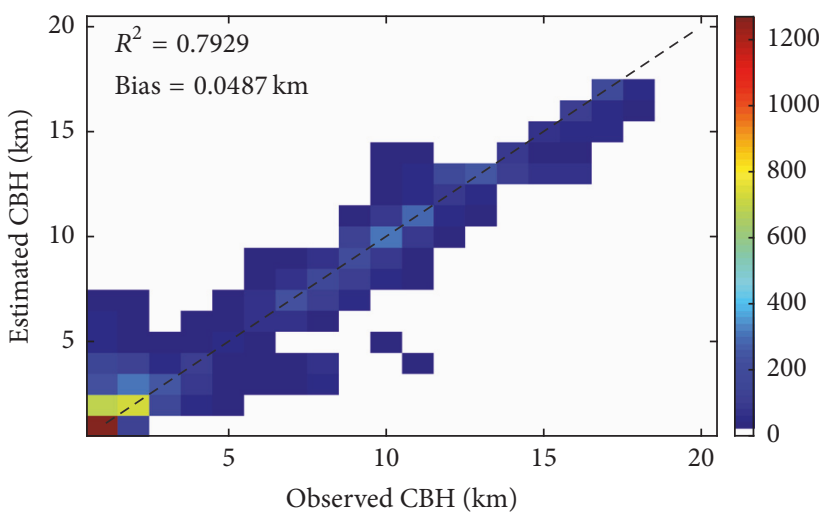

(b)

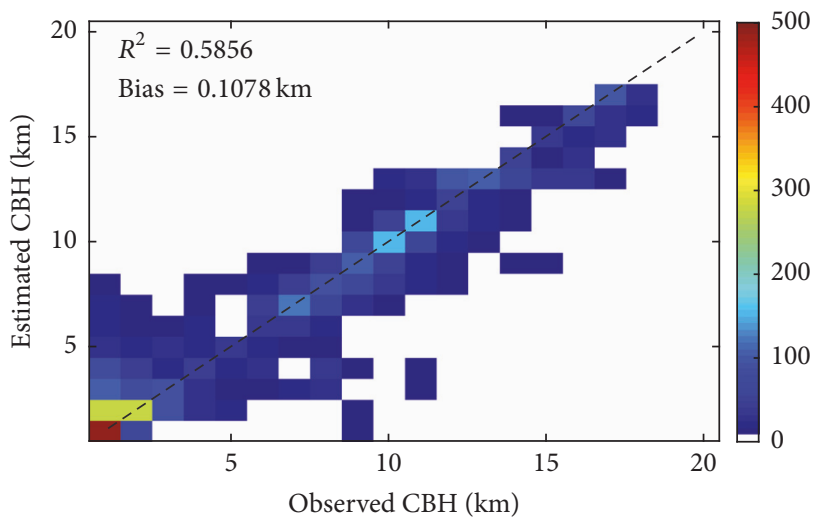

(d)

FIGURE 9: Scatterplots of the estimated and observed CBHs. Color bars indicate the number of data points. (a), (b), (c), (d) denote the range of separation distance between donor and recipient points which is $0 \sim 100 \mathrm{~km}, 101 \sim 200 \mathrm{~km}, 201 \sim 400 \mathrm{~km}$, and $401 \sim 600 \mathrm{~km}$, respectively. 


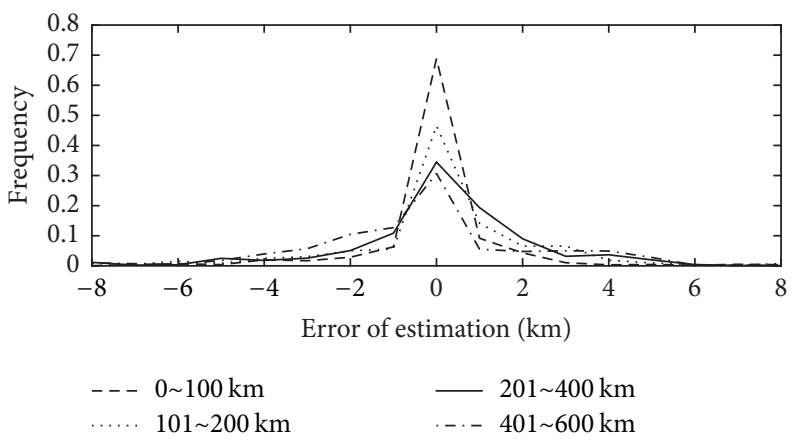

FIGURE 10: The probability density functions of differences between the estimated and observed CBHs.

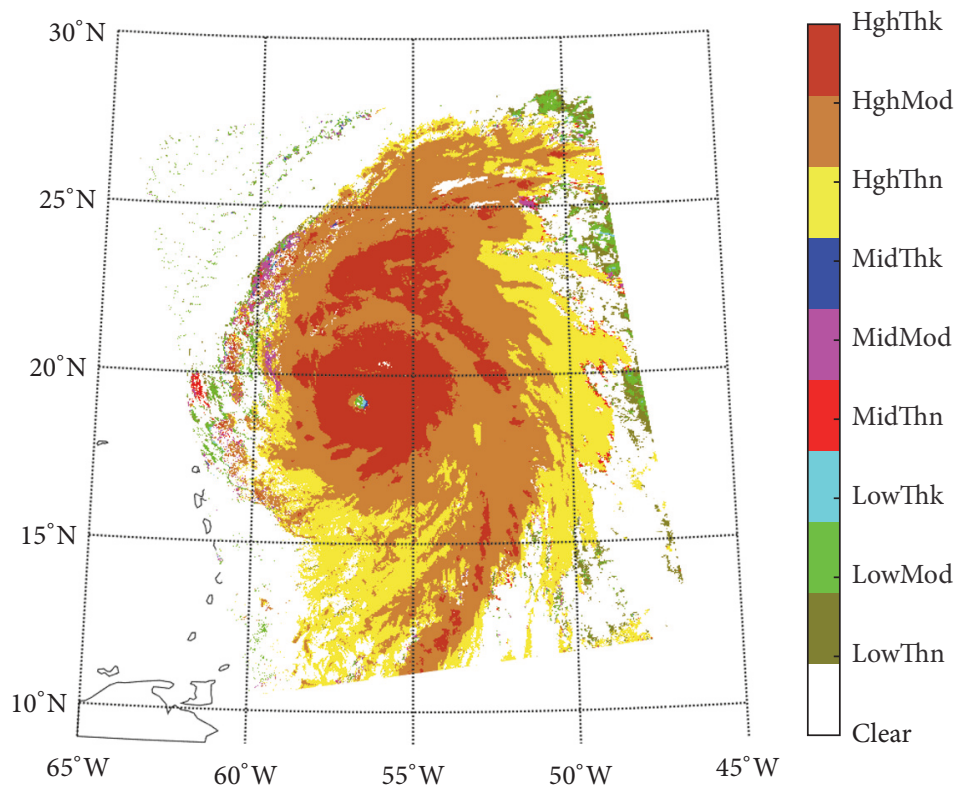

FIgURE 11: ISCCP cloud-type classification of TC Bill as observed by Aqua MODIS on August 19, 2009.

[42], which for many cirrus cloud types occurs a considerable $(>1 \mathrm{~km})$ distance below the geometric cloud top owing to characteristically small ice water paths. For the pixels of CTH greater than $10 \mathrm{~km}$ in the current example, these differences were found to be about $1 \mathrm{~km}$, and the maximum differences are no more than $3 \mathrm{~km}$.

MODIS's CTH results are shown in Figure 15(a). CTH values estimated using the Constrained Maximum Donors algorithm described in Section 4 (replacing CBH with CTH as the "donor" information) are shown in Figure 15(b). The results show that the reconstructed CTH field is similar to those of MODIS. The retrieved CTH results are in Figure 15(b). Since the donor pixels in Figure 15(b) come from CloudSat/CALIPSO, the retrieval CTHs in Figure 15(b) are mostly higher than that in Figure 15(a), since there are few donor points whose CTH is less than $12 \mathrm{~km}$. The results are also consistent with Figure 14, which indicate a more uniform $\mathrm{CTH}$ than what was suggested by MODIS. The reconstructed CTH also shows a considerable difference near thin cloud edges, such as area $\left(24^{\circ} \mathrm{N} \sim 27^{\circ} \mathrm{N},-57.5^{\circ} \mathrm{W} \sim-56^{\circ} \mathrm{W}\right)$ and at the periphery of the cirrus shelf throughout Figure 15(b).

\section{Conclusions and Discussion}

Combining CloudSat/CPR and CALIPSO/CALIOP with Aqua/MODIS active and passive sensors, $\mathrm{CBH}$ estimation algorithm based on ISCCP cloud-type classification and weighted distance is demonstrated. Following Miller et al. [27], the essence of this algorithm is the matching of the same cloud-type donor points (whose CVS were obtained from active sensor data) with recipient points within passive sensor field of view. The weighted average of all donor $\mathrm{CBH}$ values is calculated and CTP and CWP constraints following Sun et al. [25] are introduced to ensure the credibility of the data. Combining active and passive sensors, we can effectively estimate $\mathrm{CBH}$ in a wide-swath imagery where CVSs are available only along the narrow active sensor cross-section, or at discrete locations within the swath as might be available from aircraft tracks or from point observations at the surface.

The ISCCP cloud classification is generally applicable to most contemporary satellite imaging radiometers and thus offers the continuity of the best, longest time series of satellite data products [29]. By using ISCCP cloud types, 


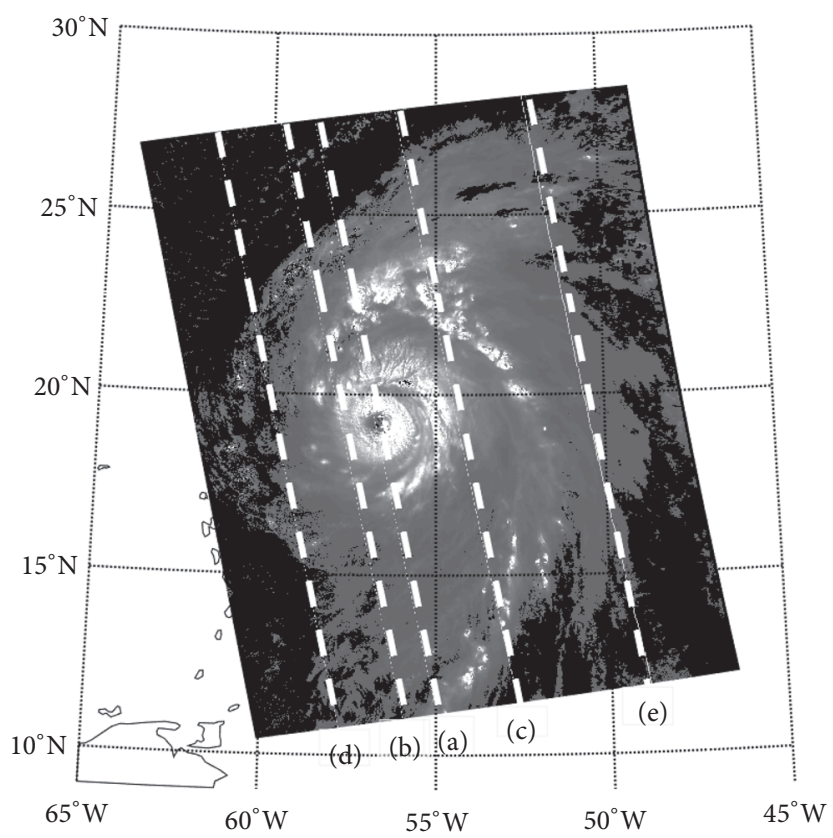

FIGURE 12: MODIS COT gray-scale image of TC Bill for the same domain presented in Figure 11. (a) CloudSat track. (b), (c), (d), (e) denote the selected scans away from the CloudSat track by $100 \mathrm{~km}, 200 \mathrm{~km}, 300 \mathrm{~km}$, and $400 \mathrm{~km}$, respectively.

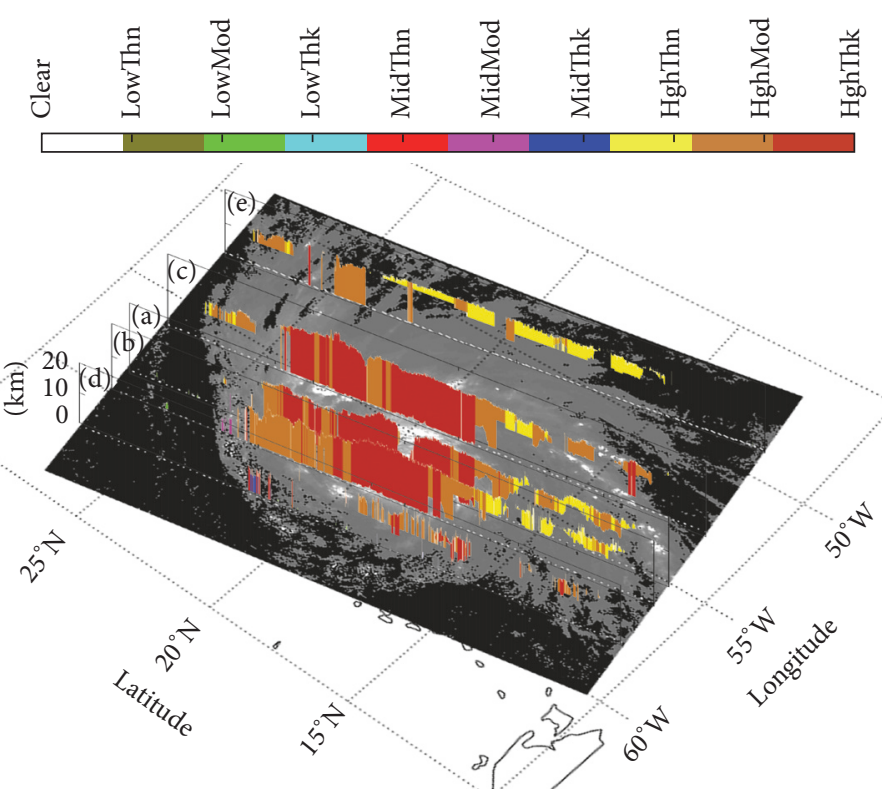

FIGURE 13: 3D view of Bill presented in Figure 11. (a) (e) have the same meanings with those of Figure 12.

$\mathrm{CBH}$ can be derived globally. And it is also suitable for other satellite remote sensors' $\mathrm{CBH}$ estimation if they can provide parameters of CTP, COT, and CWP.

The algorithm is validated by using A-Train matching datasets from January to December in 2010. The probability density function of differences between the estimated and observed CBHs is approximately normal distribution, and the absolute error is mainly within $1 \mathrm{~km}$ (growing as a function of range between donor and recipient points). The $3 \mathrm{D}$ structure of tropical storm Bill was reconstructed and the results were validated by comparing CTH of reconstruction with MODIS $\mathrm{CTH}$ product. The results from these two ways have a good consistency in $\mathrm{CTH}$ distribution range but reconstructed CTHs are mostly higher than that of MODIS for higher CTH of donor points.

Although $\mathrm{CBH}$ can be estimated within a certain error range, only single-layer clouds identified by MODIS were considered in this paper. There are some inherent difficulties 


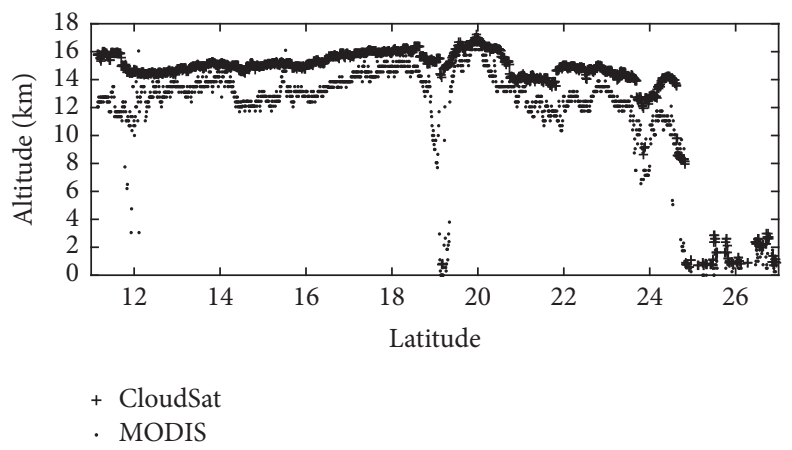

FIgURE 14: MODIS and CloudSat/CALIPSO CTH retrieval product of TC Bill.

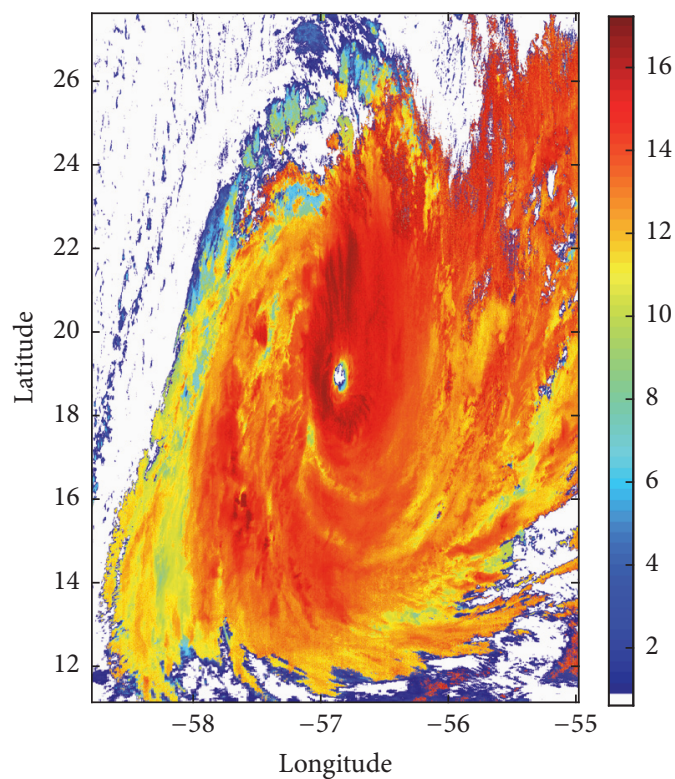

(a)

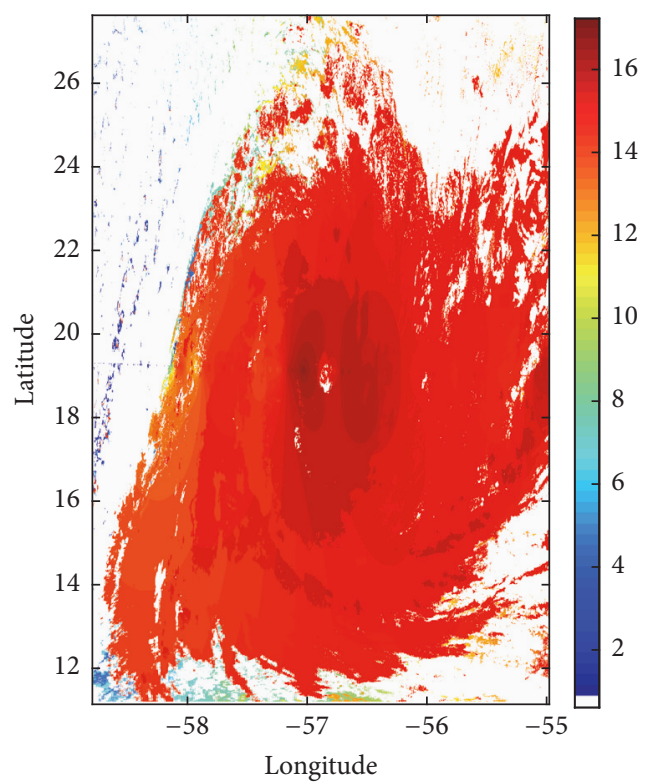

(b)

FIGURE 15: Comparison of MODIS CTH product (a) and retrieved CTH results (b) using the algorithm.

in $\mathrm{CBH}$ estimation for multilayer clouds, and the technique should be used with caution with multilayered cloud systems which are suspected (either via multispectral detection techniques or as inferred from numerical weather prediction fields). In addition, estimated $\mathrm{CBH}$ results would be inaccurate for strong signal attenuation in the case of heavy precipitation. In future work, we will consider passive microwave data, which can help to identify multilayer cloud and observe precipitating cloud systems, so as to improve the general utility and accuracy of these important $\mathrm{CBH}$ estimates.

\section{Conflicts of Interest}

The authors declare that they have no conflicts of interest.

\section{Acknowledgments}

The authors thank Yoo-Jeong Noh for helpful discussions. They gratefully acknowledge the NASA CloudSat DPC and
Goddard Space Flight Center for offering the data used in this study. This paper is supported by the National Natural Science Foundation of China (Grant no. 41575020).

\section{References}

[1] V. Ramanathan, R. D. Cess, E. F. Harrison et al., "Cloudradiative forcing and climate: results from the earth radiation budget experiment," Science, vol. 243, no. 4887, pp. 57-63, 1989.

[2] J. R. Norris, R. J. Allen, A. T. Evan, M. D. Zelinka, C. W. O’Dell, and S. A. Klein, "Evidence for climate change in the satellite cloud record," Nature, vol. 536, no. 7614, pp. 72-75, 2016.

[3] X. Song, X. Zhai, L. Liu, and S. Wu, "Lidar and ceilometer observations and comparisons of atmospheric cloud structure at nagqu of tibetan plateau in 2014 Summer," Atmosphere, vol. 8, no. 1, article no. 9, 2017.

[4] S. K. Allen, G. Plattner, A. Nauels, Y. Xia, D. Qin, and T. F. Stocker, Climate Change 2013: The Physical Science Basis. Contribution of Working Group I to the Fourth Assessment Report of the Intergovernmental Panel on Climate Change, vol. 7, Cambridge Univ. Press, 2013. 
[5] World Meteorological Day, "23 march 2017 pakistan day," https://public.wmo.int/en/WorldMetDay2017.

[6] P. J. Webster and G. L. Stephens, “Tropical upper-tropospheric extended clouds: inferences from winter MONEX.", Journal of the Atmospheric Sciences, vol. 37, no. 7, pp. 1521-1541, 1980.

[7] B. L. Madhavan, Y. He, Y. Wu, B. Gross, F. Moshary, and S. Ahmed, "Development of a ground based remote sensing approach for direct evaluation of Aerosol-Cloud interaction," Atmosphere, vol. 3, no. 4, pp. 468-494, 2012.

[8] R. L. Vislocky and J. Michael Fritsch, "An automated, observations-based system for short-term prediction of ceiling and visibility," Weather and Forecasting, vol. 12, no. 1, pp. 31-43, 1997.

[9] J. R. Mecikalski, W. F. Feltz, J. J. Murray et al., "Aviation applications for satellite-based observations of cloud properties, convection initiation, in-flight icing, turbulence, and volcanic ash," Bulletin of the American Meteorological Society, vol. 88, no. 10, pp. 1589-1607, 2007.

[10] O. Danne, M. Quante, E. Raschke, and C. Weitkamp, "Investigations of cloud layer base and top heights from $95 \mathrm{GHz}$ radar reflectivity data," Physics and Chemistry of the Earth, Part B: Hydrology, Oceans and Atmosphere, vol. 24, no. 3, pp. 167-171, 1999.

[11] P. Kollias, E. E. Clothiaux, M. A. Miller, B. A. Albrecht, G. L. Stephens, and T. P. Ackerman, "Millimeter-wavelength radars: New frontier in atmospheric cloud and precipitation research," Bulletin of the American Meteorological Society, vol. 88, no. 10, pp. 1608-1624, 2007.

[12] G. Martucci, C. Milroy, and C. D. O’Dowd, "Detection of cloud-base height using Jenoptik CHM15K and Vaisala CL31 ceilometers," Journal of Atmospheric and Oceanic Technology, vol. 27, no. 2, pp. 305-318, 2010.

[13] X. Sun, C. Qin, J. Qin, L. Liu, and Y. Hu, "Ground-based infrared remote sensing based on the height of middle and low cloud," International Journal of Remote Sensing, vol. 16, pp. 166-173, 2012.

[14] J. Wang and W. B. Rossow, "Determination of cloud vertical structure from upper-air observations," Journal of Applied Meteorology, vol. 34, no. 10, pp. 2243-2258, 1995.

[15] J. M. Forsythe, T. H. Vonder Haar, and D. L. Reinke, "Cloud-base height estimates using a combination of meteorological satellite imagery and surface reports," Journal of Applied Meteorology, vol. 39, no. 12, pp. 2336-2347, 2000.

[16] J. M. Li, Y. H. Yi, K. Stamnes et al., "A new approach to retrieve cloud base height of marine boundary layer clouds," Geophysical Research Letters, vol. 40, no. 16, pp. 4448-4453, 2013.

[17] E. Efon, A. Lenouo, D. Monkam, and D. Manatsa, "Cloud properties during active and break spells of the West African summer monsoon from CloudSat-CALIPSO measurements," Journal of Atmospheric and Solar-Terrestrial Physics, vol. 145, pp. 1-11, 2016.

[18] K. D. Hutchison, "The retrieval of cloud base heights from MODIS and three-dimensional cloud fields from NASA's EOS aqua mission," International Journal of Remote Sensing, vol. 23, no. 24, pp. 5249-5265, 2002.

[19] K. Hutchison, E. Wong, and S. C. Ou, "Cloud base heights retrieved during night-time conditions with MODIS data," International Journal of Remote Sensing, vol. 27, no. 14, pp. 28472862, 2006.

[20] K. E. Fitch, K. D. Hutchison, K. S. Bartlett, R. S. Wacker, and K. C. Gross, "Assessing VIIRS cloud base height products with data collected at the Department of Energy Atmospheric Radiation
Measurement sites," International Journal of Remote Sensing, vol. 37, no. 11, pp. 2604-2620, 2016.

[21] C. J. Seaman, Y.-J. Noh, S. D. Miller, A. K. Heidinger, and D. T. Lindsey, "Cloud-base height estimation from VIIRS. part I: Operational algorithm validation against CloudSat," Journal of Atmospheric and Oceanic Technology, vol. 34, no. 3, pp. 567-583, 2017.

[22] Y.-J. Noh, J. M. Forsythe, S. D. Miller et al., "Cloud-base height estimation from VIIRS. part II: A statistical algorithm based on A-train satellite data," Journal of Atmospheric and Oceanic Technology, vol. 34, no. 3, pp. 585-598, 2017.

[23] H. R. Li, X. J. Sun, L. Liu, and R. W. Zhang, "Cloud base height estimation based on template matching," Journal of the Meteorological Sciences, vol. 35, pp. 610-615, 2015.

[24] H.-R. Li and X.-J. Sun, "Retrieving cloud base heights via the combination of CloudSat and MODIS observations," in Proceedings of the Remote Sensing of the Atmosphere, Clouds, and Precipitation V, October 2014.

[25] X. J. Sun, H. R. Li, H. W. Barker, R. W. Zhang, Y. B. Zhou, and L. Liu, "Satellite-based estimation of cloud-base heights using constrained spectral radiance matching," Quarterly Journal of the Royal Meteorological Society, vol. 142, no. 694, pp. 224-232, 2016.

[26] H. W. Barker, M. P. Jerg, T. Wehr, S. Kato, D. P. Donovan, and R. J. Hogan, "A 3D cloud-construction algorithm for the EarthCARE satellite mission," Quarterly Journal of the Royal Meteorological Society, vol. 137, no. 657, pp. 1042-1058, 2011.

[27] S. D. Miller, J. M. Forsythe, P. T. Partain et al., "Estimating threedimensional cloud structure via statistically blended satellite observations," Journal of Applied Meteorology and Climatology, vol. 53, no. 2, pp. 437-455, 2014.

[28] R. A. Schiffer and W. B. Rossow, "The International Satellite Cloud Climatology Project (ISCCP): the first project of the World Climate Research Programme," Bulletin - American Meteorological Society, vol. 64, no. 7, pp. 779-784, 1983.

[29] I. I. Mokhov and M. E. Schlesinger, "Analysis of global cloudiness: 1. Comparison of Meteor, Nimbus 7, and International Satellite Cloud Climatology Project (ISCCP) satellite data," Journal of Geophysical Research, vol. 98, no. 7, pp. 12-868, 1993.

[30] G. L. Stephens, D. G. Vane, R. J. Boain et al., "The cloudsat mission and the A-Train: A new dimension of space-based observations of clouds and precipitation," Bulletin of the American Meteorological Society, vol. 83, no. 12, pp. 1771-1742, 2002.

[31] J. M. Haynes, C. Mitrescu, and G. L. Stephens, "A combined lidar and radar retrieval of cloud optical properties," in Proceedings of the Lidar Remote Sensing for Industry and Environmental Monitoring V, pp. 88-99, usa, November 2004.

[32] R. Marchand, G. G. Mace, T. Ackerman, and G. Stephens, "Hydrometeor detection using Cloudsat - An earth-orbiting 94-GHz cloud radar," Journal of Atmospheric and Oceanic Technology, vol. 25, no. 4, pp. 519-533, 2008.

[33] D. L. Wu, S. A. Ackerman, R. Davies et al., "Vertical distributions and relationships of cloud occurrence frequency as observed by MISR, AIRS, MODIS, OMI, CALIPSO, and CloudSat," Geophysical Research Letters, vol. 36, no. 9, Article ID L09821, 2009.

[34] J. Li, W. P. Menzel, Z. Yang, R. A. Frey, and S. A. Ackerman, "High-spatial-resolution surface and cloud-type classification from MODIS multispectral band measurements," Journal of Applied Meteorology, vol. 42, no. 2, pp. 204-226, 2003. 
[35] W. B. Rossow and R. A. Schiffer, "Advances in Understanding Clouds from ISCCP," Bulletin of the American Meteorological Society, vol. 80, no. 11, pp. 2261-2287, 1999.

[36] C. J. Hahn, W. B. Rossow, and S. G. Warren, "ISCCP Cloud Properties Associated with Standard Cloud Types Identified in Individual Surface Observations," Journal of Climate, vol. 14, no. 1, pp. 11-28, 2001.

[37] T. Wang, E. J. Fetzer, S. Wong, B. H. Kahn, and Q. Yue, "Validation of MODIS cloud mask and multilayer flag using CloudSat-CALIPSO cloud profiles and a cross-reference of their cloud classifications," Journal of Geophysical Research: Atmospheres, vol. 121, no. 19, pp. 11620-11635, 2016.

[38] W. P. Menzel and R. A. Frey, "Cloud top properties and cloud phase algorithm theoretical basis document," 2013.

[39] S. D. Miller, G. L. Stephens, and R. T. Austin, "GOES 10 cloud optical property retrievals in the context of vertically varying microphysics," Journal of Geophysical Research Atmospheres, vol. 106, no. 16, Article ID 2000JD000057, pp. 17981-17995, 2001.

[40] E. Weisz, J. Li, W. P. Menzel, A. K. Heidinger, B. H. Kahn, and C.Y. Liu, "Comparison of AIRS, MODIS, CloudSat and CALIPSO cloud top height retrievals," Geophysical Research Letters, vol. 34, no. 17, Article ID L17811, 2007.

[41] H. B. Kahn, T. M. Chahine, L. G. Stephens et al., "Cloud type comparisons of AIRS, CloudSat, and CALIPSO cloud height and amount," Atmospheric Chemistry \&amp; Physics Discussions, vol. 7, no. 5, pp. 1231-1248, 2007.

[42] P. W. Menzel, R. A. Frey, H. Zhang et al., "MODIS global cloudtop pressure and amount estimation: Algorithm description and results," Journal of Applied Meteorology and Climatology, vol. 47, no. 4, pp. 1175-1198, 2008. 

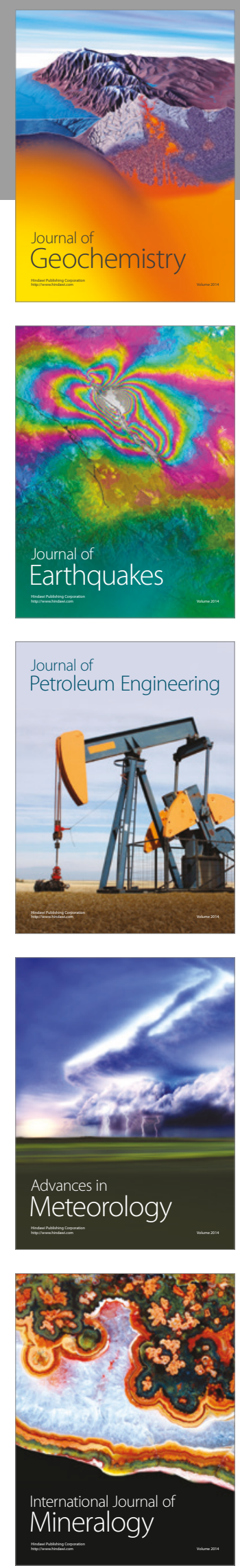
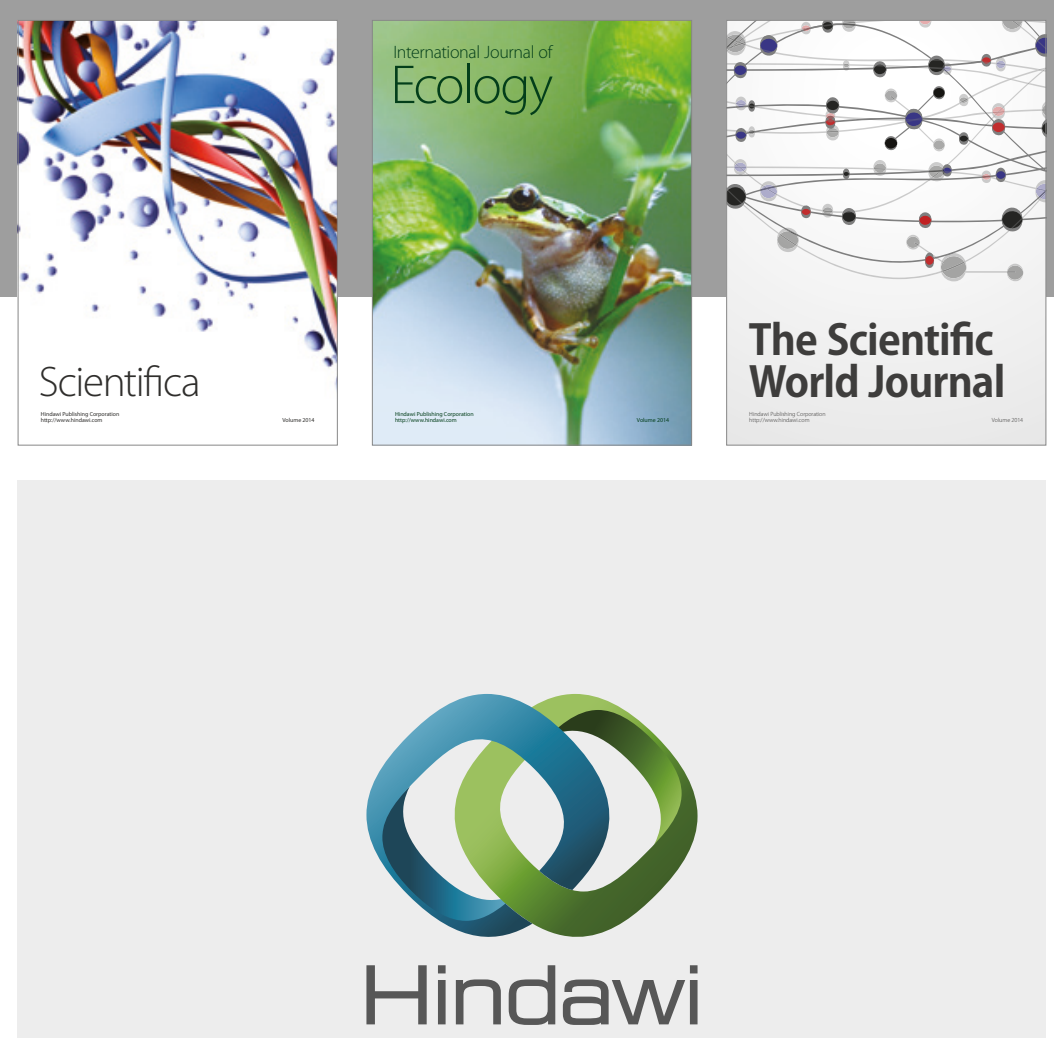

Submit your manuscripts at

https://www.hindawi.com
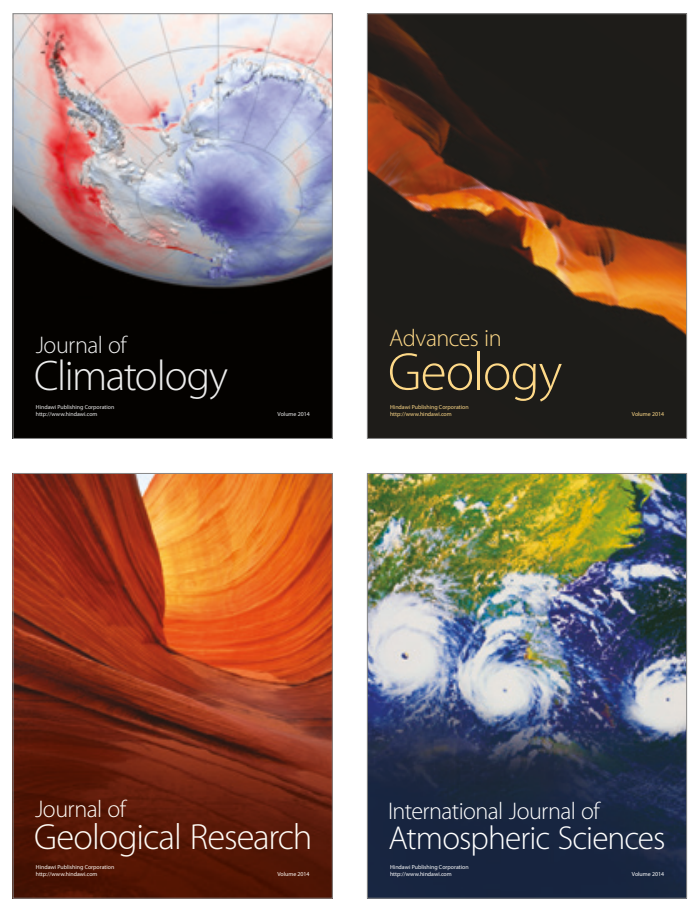

The Scientific

World Journal
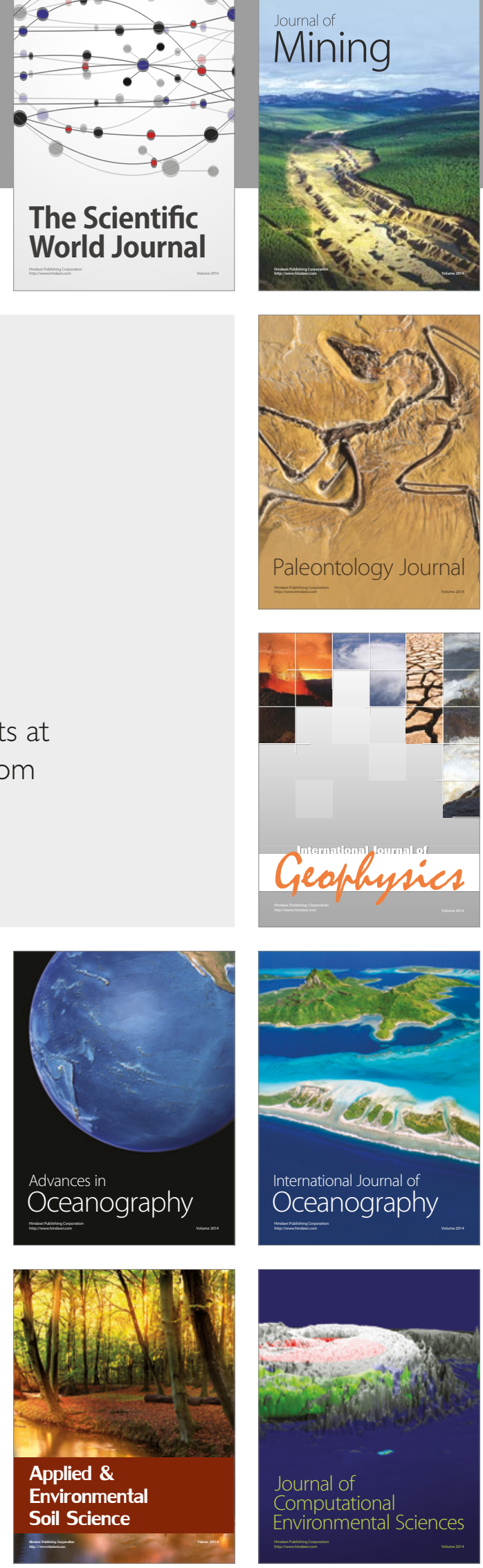